J. Ginseng Res.

Vol. 31, No. 3, 142-146 (2007)

\author{
경흔적 수에 의한 수삼의 연근판별 \\ 이성식 * 이장호 · 안인옥 · 김영창* - 방경환* - 현동윤* \\ $\mathrm{KT \& G}$ 중앙연구원, *농촌진흥청 작물과학원 \\ (2007년 7월 18일 접수; 2007년 9월 4일 수리)
}

\title{
Identification of the Age of Fresh Ginseng Root According to Number of Stem Vestiges in Rhizome
}

\author{
Sung-Sik Lee ${ }^{\#}$, Jang-Ho Lee, In-Ok Ahn, Young-Chang Kim* \\ Kyong-Hwan Bang* and Dong-Yun Hyun* \\ ${ }^{\#} K T \& G$ Central Research Institute, Suwon 441-480, Korea \\ *National Institute of Crop Science, RDA Suwon 441-857, Korea
}

(Received July 18, 2007; Accepted September 4, 2007)

\begin{abstract}
This experiment was conducted to find identification of ginseng root's age using the number of stem vestiges in rhizome. The number of stem vestiges in rhizome is a useful key to confirm the age of ginseng root as follow : 4-year-old root has two, 5-year-old root has three, 6-year-old root has four. The distribution of stem vestiges in rhizome each year root are as follow : 2 stem vestiges in 4-year-old root is $89.5 \%, 3$ stem vestiges in 5-year-old root is $79.7 \%$, 4 stem vestiges in 6-year-old root is $46.3 \%$. However, the limiting factors of identification of ginseng root's age using the number of stem vestiges in rhizome is appearance of multi-stem per plant and appearance of destroyed stem vestige in rhizome. The ratio of appearance of multi-stem per plant and destroyed stem vestige in rhizome are increased according to root age.
\end{abstract}

Key words : stem vestiges, rhizome, root's age

\section{서 론}

인삼은 다년생 약용작물로 동일 장소에서 3-5년간 생육하며, 생육된 인삼은 상업적 목적에 따라 년생 별로 채굴하여 유통 된다. 유통되는 인삼은 연근과 크기에 따라 가격이 다르며, 고년근 일수록 가격이 비싸기 때문에 시장에서 종종 연근판 별을 위장하여 유통질서를 무너뜨리는 일이 발생하는 경우가 있다. 현행 인삼산업법에는 인삼경작자가 5 년근 이상의 수삼 을 수확하고자 할 때에는, 농림부령이 정하는 바에 의하여 조 합에 연근 확인을 신청할 수 있고, 조합은 검사담당직원으로 하여금 수확에 입회하여 수삼의 연근을 확인하도록 하고 있 다. 또한 시행규칙으로 연근판별 세부기준을 마련하고 있는데,

\#본 논문에 관한 문의는 이 저자에게로 (전화) 016-780-0399; (팩스) 031-419-9434 (E-mail) sungslee2@naver.com
연근검사의 기준은 머리, 몸통 및 표피의 형태, 다리부분의 발달정도, 절단시 나이테 등을 육안 또는 발색시켜 판별하도 록 되어있다1).

동 시행규칙의 세부사항에서 " 6 년근의 머리형태는 5 년근에 비하여 굵고 길며 4 개 이상의 명확한 줄기(경)흔적이 있음”으 로 명시되어있다. 그러나 경흔적에 의한 연근판별의 경우, 6 년 근에서 4 개 이상의 명확한 경흔적 발생 분포비율이 다양하게 나타나서 연근판별에 혼란이 발생하고, 인삼산업체에서 연근증 명에 어려움을 호소하고 있는 실정이다. 그러므로, 이러한 연 근판별의 기준은 실용적인 면에서 보완과 개선이 필요한 실정 인데, 지금까지 인삼의 연근을 판별하는 방법으로는 근중 및 지근발달형태 판별법 ${ }^{2,3)}$, 뇌두판별법 ${ }^{2)}$, 나이테 판별법 3,4 , ginsenosides 함량법 ${ }^{5)}$, 분비도관의 판별법 ${ }^{6)}$ 등이 시도되었다. 그러나, 근중 및 지근 발달형태 판별법은 정확도가 떨어지고, 나이테판별법과 ginsenosides 함량법 및 분비도관의 판별법은 파괴적인 방법으로 제약이 있다. 따라서 본 연구는 비파괴적 
인 방법으로 간편히 판별할 수 있는 뇌두판별법을 이용하여 연근판별의 실용화가 가능한지 검토하기 위하여 본 연구를 실 시하였다.

\section{재료 및 방법}

본 실험에 사용된 수삼은 고려인삼 (Panax ginseng C.A. Meyer) 자경재래종, 천풍, 연풍 및 금풍으로 2005년 9 월 29 일에서 10 월 26 일에 $\mathrm{KT \& G}$ 중앙연구원 생물자원연구소 포 장(수원) 및 산지포장에서(서산, 논산, 예산, 이천, 여주, 포천, 파주, 적성, 안성, 화성, 풍기, 임실, 홍천, 춘천) $4,5,6$ 년생 수삼시료를 채취하여 물로 세척한 후 사용하였다. 경흔적은 동체와 뇌두의 경계선으로부터 뇌두방향으로 경흔적의 수를 육안으로 조사하였다. 연근별 경수 분포비율은 $4,5,6$ 년근을 조사하였고, 분포비율 조사는 연근별로 전체조사 개체수에 대 한 각각 분포경의 개체수 합계를 비율로 표시하였고, 다경발 생율은 조사 전체개체수에 대한 뿌리당 2 경 이상 개체수를 비율로 나타내었다. 품종별 경수 분포비율은 재배면적이 많은 자경재래종과 신품종인 천풍, 연풍 및 금풍의 6년근을 사용하 였으며, 분포비율 조사는 품종별로 전체조사 개체수에 대한 각각 분포경의 개체수 합계를 비율로 표시하였다. 경수별 경 흔적수 조사는 6 년근 자경재래종을 사용하였고, 경흔적이 파 손된 개체는 포함하지 않았다. 품종별 경흔적수 조사는 자경 재래종, 천풍, 연풍 및 금풍의 6년근을 사용하였다. 연생별 경흔적수 조사는 우리나라 인삼산지의 약 $95 \%$ 정도 재배되고 있는 자경재래종을 사용하였고, 15 개 산지포장에서 9,691 개체 를 조사하였다.

\section{결 과}

\section{1. 경흔적의 특성}

인삼의 줄기가 고사되면 지상부는 마르고 뿌리의 선단부에 있는 뇌두조직에 이층이 형성된다. 뇌두부위에 생긴 이층 자 국은 뇌두부위가 움푹 파이고 줄기의 잔해흔적이 남게 되는 데 이것을 경흔적이라 부른다. 그러나 1,2 년생 때의 경흔적 은 크기가 작고, 고년근이 되면 그 흔적이 동체와 뇌두의 경 계면 속에 묻혀서 식별이 어려우나, 3년생 이상의 경흔적 부 터는 식별이 용이한데, 경흔적수가 보통 4 년생은 2 개, 5 년생 은 3 개, 6 년생은 4 개가 존재한다 (Fig. 1). 그러므로 3년생 이 상의 경흔적수에 보이지 않는 1,2 년생의 경흔적 수 2 를 더 하면 인삼의 연근 판별을 추정할 수 있는데, 즉 연근=경흔적 수 +2 가 된다.

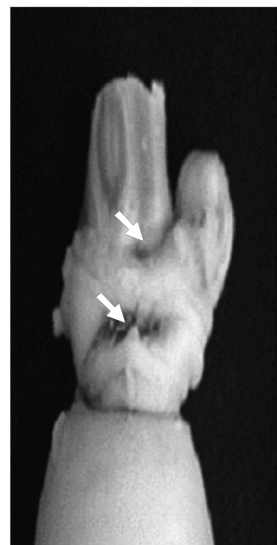

A

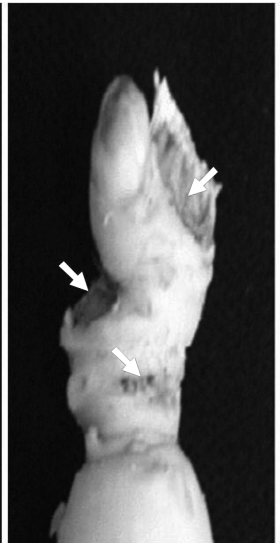

B

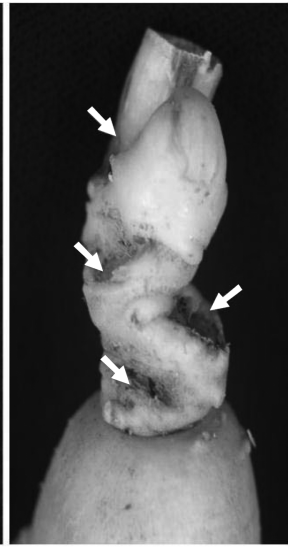

$\mathrm{C}$
Fig. 1. Stem vestige in rhizome. (A) 4-year-old root (B) 5-yearold root (C) 6-year-old root.
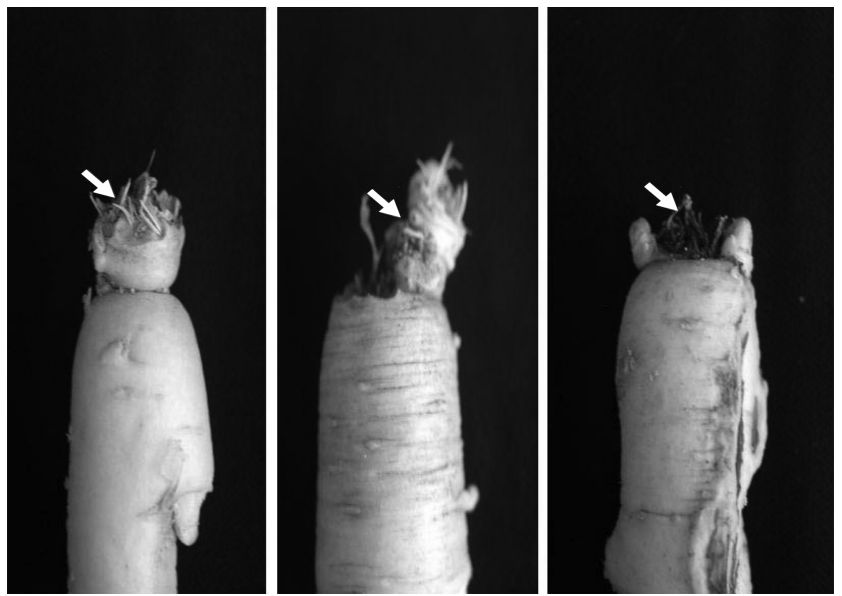

Fig. 2. Destroyed stem vestige in rhizome.

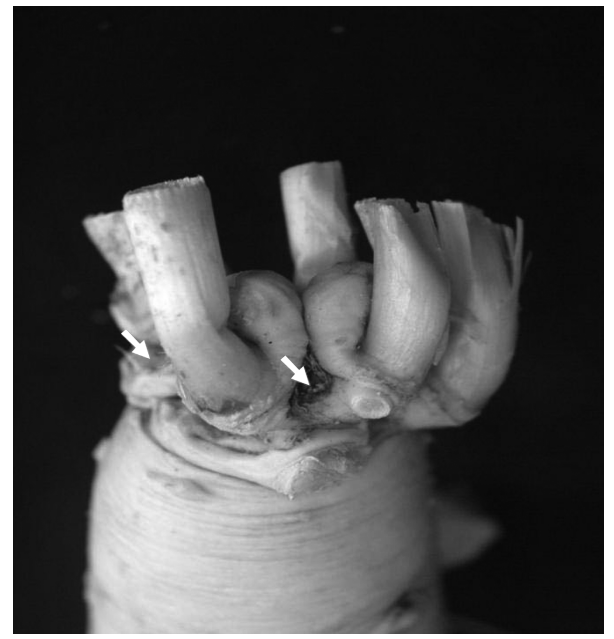

Fig. 3. Buried stem vestige in rhizome under multi-stem.

\section{2. 경흔적 식별 장해요인}

경흔적수를 이용하여 인삼의 연근을 판별하는데 장해요인 
으로는 뇌두가 파손되어 경흔적수 식별이 불가능한 경우가 있 고(Fig. 2), 다경발생에 의해 경흔적이 지하경에 묻혀서 식별 이 어려운 경우가 있었다(Fig. 3).

\section{3. 다경발생 현황}

다경발생이 경흔적수 식별에 제약요인 인데 연생별로 다경 발생 비율을 보면 연생이 증가 할 수 록 다경발생이 증가 되었는데, 4 년근이 $27.8 \%, 5$ 년근이 $35.2 \%, 6$ 년근이 $40.7 \%$ 였다(Table 1). 또한 다경발생은 연근뿐만 아니라 품종간에도
차이가 나타나서 6 년근 조사에서 연풍이 $56.8 \%$ 로 자경재래종 $33.3 \%$ 보다 높았으나, 천풍은 $17.9 \%$, 금풍은 $8.2 \%$ 로 자경재 래종 보다 낮았다 (Table 2). 다경발생에 의해 경흔적수가 묻 히는지를 알기위하여 6 년생에서 경수별 경흔적수를 조사한 결 과는 Table 3 과 같다. 경흔적수로 6 연근판별이 가능한, 경흔 적수 4 개의 식별 비율이 1 경에서는 $80.0 \%$ 였으나, 2 경에서 는 $57.0 \%, 3$ 경에서 $47.2 \%$, 4 경에서 $45.0 \%$, 5경에서 $33.3 \%$ 로 경수가 증가 할 수 록 낮아져서, 경수가 증가할 수 록 년 근판별의 정확도는 낮아졌다. 경수는 인삼품종별로도 차이가 있었는데 (Table 2), 품종별로 다경발생의 차이에 의해 경흔적

Table 1. Distribution of number of stem per plant at various root age

(Unit : \%)

\begin{tabular}{|c|c|c|c|c|c|c|c|}
\hline \multirow{2}{*}{ Root Age } & \multicolumn{6}{|c|}{ Number of stem } & \multirow{2}{*}{$\begin{array}{l}\text { The ratio of } \\
\text { multi-stem }\end{array}$} \\
\hline & 1 & 2 & 3 & 4 & above 5 & total & \\
\hline 4-year-old & 72.2 & 27.3 & 0.5 & 0 & 0 & 100 & 27.8 \\
\hline 5-year-old & 64.8 & 31.8 & 2.9 & 0.5 & 0 & 100 & 35.2 \\
\hline 6-year-old & 59.3 & 34.2 & 4.6 & 1.4 & 0.5 & 100 & 40.7 \\
\hline
\end{tabular}

*The ratio of multi stem(above 2 stem) to total plants.

- Sampled 9691 roots at 15 ginseng fields.

Table 2. Distribution of number of stem per plant at various cultivars in 6-year-old ginseng plant

(Unit : \%)

\begin{tabular}{|c|c|c|c|c|c|c|c|}
\hline \multirow{2}{*}{ Cultivars } & \multicolumn{6}{|c|}{ Number of stem } & \multirow{2}{*}{$\begin{array}{l}\text { The ratio of } \\
\text { multi-stem }\end{array}$} \\
\hline & 1 & 2 & 3 & 4 & above 5 & total & \\
\hline Jakyungjong & 66.7 & 22.3 & 8.8 & 1.4 & 0.8 & 100 & 33.3 \\
\hline Chunpoong & 82.1 & 10.3 & 6.8 & 0.8 & 0 & 100 & 17.9 \\
\hline Yunpoong & 43.2 & 40.3 & 13.1 & 2.1 & 1.3 & 100 & 56.8 \\
\hline Geumpoong & 91.9 & 7.5 & 0.6 & 0 & 0 & 100 & 8.2 \\
\hline
\end{tabular}

*The ratio of multi stem(above 2 stem) to total plants.

- Sampled 9691 roots at 15 ginseng fields.

Table 3. The number of stem vestige in rhizome at various stems in 6-year-old root

(Unit : \%)

\begin{tabular}{cccccc}
\hline \hline \multirow{2}{*}{ Root Age } & Number of & \multicolumn{3}{c}{ Number of stem vestige in rhizome } & \multirow{2}{*}{ Total } \\
\cline { 2 - 5 } & stem & 2 & 3 & 4 & 100 \\
& 1 & 0 & 20.0 & 50.0 & 100 \\
6-year-old & 2 & 0 & 53.0 & 47.2 & 100 \\
& 3 & 0 & 55.0 & 45.0 & 100 \\
& 4 & 0 & 66.7 & 33.3 & 100 \\
\hline
\end{tabular}

- Samples of destroied stem vestige in rhizome are not included .

- Sampled 9691 roots at 15 ginseng fields.

Table 4. The number of stem vestige in rhizome at various ginseng cultivars at 6-year-old root

(Unit : \%)

\begin{tabular}{lccccc}
\hline \hline \multirow{2}{*}{ Cultivars } & \multicolumn{3}{c}{ Number of stem vestige } & $\begin{array}{c}\text { Destroied stem } \\
\text { vestige }\end{array}$ & Total \\
\cline { 2 - 4 } & 2 & 3 & 4 & 23.5 & 100 \\
Jakyungjong & 0.3 & 24.6 & 61.6 & 18.5 & 100 \\
Chunpoong & 0 & 15.2 & 48.0 & 20.9 & 100 \\
Yunpoong & 0.1 & 31.0 & 70.0 & 12.6 & 100 \\
Geumpoong & 0 & 17.4 & &
\end{tabular}

- Sampled 9691 roots at 15 ginseng fields. 
Table 5. The number of stem vestige in rhizome at various root age

\begin{tabular}{ccccccc}
\hline \hline \multirow{2}{*}{ Root Age } & \multicolumn{3}{c}{ Number of stem vestige } & \multicolumn{2}{c}{$\begin{array}{c}\text { Destroyed stem } \\
\text { vestige }\end{array}$} & Total \\
\cline { 2 - 5 } & 1 & 2 & 3 & 4 & $5.3 \pm 0.7$ & 100 \\
4-year-old & $2.4 \pm 0.4$ & $89.5 \pm 1.3$ & $2.8 \pm 0.7$ & - & $9.6 \pm 1.5$ & 100 \\
5-year-old & - & $10.8 \pm 2.7$ & $79.7 \pm 1.3$ & - & $24.0 \pm 1.8$ & 100 \\
6-year-old & - & $0.5 \pm 0.3$ & $29.2 \pm 2.6$ & $46.3 \pm 3.6$ & \\
\hline
\end{tabular}

- Sampled 9691 roots at 15 ginseng fields.

${ }^{x}$ Mean \pm standard error.

수가 묻히는지 알기위하여 6년생에서 품종별로 경흔적수를 조 사한 결과는 Table 4 와 같다. 경흔적수 4 개 식별 비율이 금 풍이 $70.0 \%$, 천풍이 $66.3 \%$ 로 자경재래종 $51.6 \%$ 보다 높았으 나, 연풍은 $48.0 \%$ 로 낮아서, 연풍품종이 경수가 많아 연근판 별의 정확도가 낮았다. 품종별 경흔적수 판별이 불가능한 개 체수의 비율은 연풍과 자경종이 $20.9-23.5 \%$ 로 높았고, 천풍이 $18.5 \%$ 로 중간이었으나, 금풍이 $12.6 \%$ 로 낮았다.

\section{4. 경흔적수에 의한 연근 판별}

지금현재 우리나라에서 재배되는 수삼의 연근판별이 경흔 적수에 의해 가능한지를 검토하기 위하여 조사한 결과는 Table 5 와 같다. 경흔적수에 의한 연근판별방법에서 경흔적수 가 4 년생은 2 개, 5 년생은 3 개, 6 년생은 4 개인데, 본 조사결 과 4 년생에서 경흔적 2 개의 발생비율이 $89.5 \%, 5$ 년생에서 경흔적 3 개의 발생비율이 $79.7 \%, 6$ 년생에서 경흔적 4 개의 발생비율이 $46.3 \%$ 였다. 이러한 자료를 근거로 연근판별 정 확도가 4 년근은 $89.5 \%, 5$ 년근은 $79.7 \%$ 로 높았으나, 6 년근은 $46.3 \%$ 로 비교적 낮았다. 경흔적수를 식별 할 수 없는 경흔적 파괴 비율이 4년생 5.3\%, 5년생 9.6\%로 비교적 낮았으나, 6 년생은 $24.0 \%$ 로 높았다.

\section{고 찰}

인삼의 줄기가 고사되면, 뇌두조직에 이층이 형성되고, 줄 기의 잔해가 남게 되는데 이것을 경흔적이라 부른다. 이러한 경흔적은 1,2 년생의 경흔적은 크기가 작아서 고년근이 되면 동체와 뇌부의 경계면에 묻혀서 식별이 어려우나 3 년생 경흔 적 부터는 식별이 용이하였다 (Fig. 1). 그러므로 경흔적수에 보이지 않는 1,2 년생의 경흔적수 2 개를 더하면 연근판별이 가능하였다. 그러나 실제 경흔적수를 이용하여 연근판별을 하 는데는 2 가지 제한요인이 있는데, 뇌두파손과 다경발생에 의 한 경우이다. 먼저 뇌두파손의 경우를 검토한 결과, 뇌두가 파손되어 경흔적수를 식별 할 수 없는 경우가 발생 되었다 (Fig. 2), 또한 뇌두 파손 개체수는 년근이 경과 할수록 많아 지고 특히 4,5 ,년생보다 6 년생에서 발생 비율이 높았다
(Table 5). 연근판별의 또다른 제한요인인 다경발생에 의해 경 흔적이 지하경에 묻혀서 식별이 어려웠으며(Fig. 3), 경수가 증가 할수록 해당연근의 경흔적수가 감소하여 연근판별의 정 밀도를 저하 시켰다 (Table 3). 이러한 다경의 발생은 고년근 으로 갈수록 증가 되었고 (Table 1), 연풍품종에서 많이 발생 되었다 (Table 2).

현재 우리나라에서 재배되는 수삼의 연근판별이 경흔적수 에 의해 가능한지를 검토한 결과, 정확도가 4 년생에서 $89.5 \%, 5$ 년생에서 $79.7 \%$ 로 비교적 높아서 활용성이 높은 것 으로 판단되었으나, 6 년생에서는 $46.3 \%$ 로 상대적으로 낮아서 연근판별 자료로 활용성은 다소 낮으나, 보조지표로 활용성은 높은 것으로 판단되었다. 더구나 인삼산업법에 연근판별기준 은 경흔적수 4 개를 모든 개체에 적용하는 것은 개선되어야 할 것이며, 본연구에서 조사된 6 년생에서 경흔적수 $46.3 \%$ 발 생율은 숙달된 전문가의 조사 성적이고, 일반인이 조사할 경 우 경흔적수 4 개 분표율은 더 낮을 가능성이 예상된다.

경흔적수에 의한 연근판별법의 정확도가 이 등2)은 1996 년 보고에서 4 년근이 $100 \%, 5$ 년근이 $96.5 \%, 6$ 년근이 $93 \%$ 로 본 연구결과 보다 높았는데, 이것은 뇌두손상율이 본연구에서 $5.0-19.4 \%$ 와 이 등 2 의 $7-18.7 \%$ 와 비슷하였으나, 다경발생율 은 본연구에서 $27.8 \%-40.7 \%$ 로 이 등 2 은 $4.6 \%-15.7 \%$ 보다 높아, 다경의 발생율 증가로 연근판별의 정확도가 낮아진 것 이 주요 요인의 하나로 생각된다. 현재로서는 경흔적수에 의 한 연근판별법은 보조 지표로 활용이 가능하다고 생각되며, 다경계통인 연풍 품종의 면적이 증가가 예상되고 있기 때문 에 6 년근의 연근판별법은 경흔적수 단일 방법으로 판별하기 에는 정확도가 점차 감소하리라 생각된다.

\section{요 약}

본 시험은 경흔적수 측정법으로 수삼의 연근을 판별하기 위 하여, $4,5,6$ 년근의 경흔적수 발생실태를 조사하였다. 경흔적 수를 이용한 연근판별법은 3 년근 경흔적부터 식별가능하여 경 흔적수에 2 를 더하면 년근판별이 가능하였다. 년근별 경흔적 수가 4 년생에서 2 개 발생율이 $89.5 \%, 5$ 년생에서 3 개 발생율 
이 $79.7 \% 6$ 년생에서 4 개 발생율이 $46.3 \%$ 로, 4,5 년근의 판 별은 가능하였으나, 6 년근 판별은 정확도가 낮아 보조자료로 활용함이 타당하였다. 경흔적을 이용한 연근 판별의 제한요인 으로 뇌두파손과 다경발생임을 확인하였고, 뇌두파손율과 다 경발생율은 년근이 증가함에 따라 증가되었다.

\section{인용문헌}

1. 농림부 : 인삼산업법, 법율 제8조(2004).

2. 이장호, 이명구, 최광태, 이성식 : 경(줄기)흔을 중심으로 한 재 배인삼의 연근판별 Korean J. Ginseng Sci. 20(1), 72-77 (1996).
3. 이종철, 안대진, 변정수 : 육묘 및 백삼건조 방법 개선 연구. 인삼연구보고서(재배분야, 재배편), 한국인삼연초연구소, 대전, p. 89-202 (1988).

4. 이종철, 안대진, 변정수 : 육묘 및 백삼건조 방법 개선 연 구. 인삼연구보고서(재배분야, 재배편), 한국인삼연초연구소, 대전, p. 215-344 (1987).

5. William, A. C., Reynolds, L. B. and John, G. H.: Influence of root age on the concentration of ginsenosides of American ginseng(Panax quinquefolium) Can. J. Plant Sci. 76, 853-6 (1996).

6. 이경환, 이성식, 이명구, 김은수 : 인삼 분비도관의 조직화학 적 염색에 의한 연근판별. J. Ginseng Res. 25(2), 101-105 (2001). 